\title{
Myeloid-related protein 8/14 levels in children with obstructive sleep apnoea
}

\author{
J. Kim*, R. Bhattacharjee ${ }^{\#}$, A.B. Snow", O.S. Capdevila ${ }^{\#}$, \\ L. Kheirandish-Gozal* and D. Gozal*
}

ABSTRACT: Obstructive sleep apnoea (OSA) is common in children and leads to multiple endorgan morbidities. Myeloid-related protein (MRP) 8/14 plays an important pathophysiological role in atherosclerosis, and plasma levels correlate with endothelial cell dysfunction. We hypothesised that MRP8/14 levels would be altered in children with OSA.

255 children (aged $7.6 \pm 1.5 \mathrm{yrs}$ ) were included after a sleep study and a morning blood sample. MRP8/14 and interleukin- 6 plasma levels were assayed using ELISA and C-reactive protein by immunoturbidometry. Endothelial function was assessed as the hyperaemic response after occlusion of the brachial artery.

Plasma log MRP8/14 levels showed apnoea/hypopnoea index (AHI) dose-dependent increases regardless of obesity. Moreover, log MRP8/14 levels correlated with log AHI $(r=0.340, p<0.001)$ after controlling for age and body mass index Z-score, and with endothelial function. Children with the highest MRP levels $\left(>1.34 \mathrm{ug} \cdot \mathrm{mL}^{-1}\right)$ had 2.4- and 5.4-fold increased odds of mild OSA and moderate-to-severe OSA, respectively, after adjusting for confounding variables.

Plasma MRP8/14 levels are associated with paediatric OSA and may reflect increased risk for cardiovascular morbidity. The short- and long-term consequences of elevated MRP8/14 on cardiovascular function in the context of paediatric OSA remain to be defined.

KEYWORDS: Atherosclerosis, endothelial dysfunction, inflammation, myeloid-related protein 8/ 14, obstructive sleep apnoea

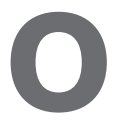
bstructive sleep apnoea (OSA) is characterised by repeated events of partial and complete upper airway obstruction during sleep, which results in disruption of normal ventilation, hypoxaemia and sleep fragmentation. Increasing evidence from several lines of investigation strongly supports the concept that OSA in adults is pathophysiologically linked to cardiovascular diseases (CVD), such as hypertension, ischaemic heart disease and cerebrovascular disease [1, 2]. Similar to adult patients with OSA, paediatric OSA has been recently associated with a high risk of cardiovascular morbidities and metabolic dysfunction, particularly among obese children [3-6]. Increased generation of reactive oxygen species and systemic inflammatory responses related to hypoxia-reoxygenation events and sleep fragmentation are mechanistically involved in acceleration and propagation of atherogenesis [7-9]. However, the mechanisms underlying the association between OSA and CVD are currently not fully understood.

Myeloid-related protein (MRP) 8 and MRP 14 are S100 proteins and serve as important calcium-binding proteins in the process of phagocytosis. Indeed, non-covalently bound MRP8/ MRP14 complexes are secreted by activated phagocytes under various inflammatory conditions [10-14]. As a corollary to these observations, MRP8/14 has been identified as an important predictor of cardiovascular disease [15, 16]. Indeed, MRP 8/14 protein complexes play an important role in atherosclerosis and are closely correlated with inflammatory processes within the endothelial wall [17, 18]. We have previously shown that children with OSA, even non-obese children, exhibit elevations in several systemic inflammatory markers that suggest the presence of increased risk for atherosclerosis [19-21]. Furthermore, we have recently shown that children with severe OSA display reversible alterations in endothelial function, when the latter is determined using post-occlusion hyperaemic response [22]. Not surprisingly, there is growing interest in the identification of biomarkers that can serve as an early detection strategy of CVD risk factors, with the anticipation that timely interventions could reduce the risk for future cardiovascular events. Based on the aforementioned considerations, we hypothesised that plasma MRP8/14 levels would

\section{AFFILIATIONS}

${ }^{*}$ Dept of Paediatrics, University of Chicago, Chicago, IL, and

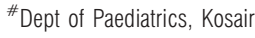
Children's Hospital Research Institute, University of Louisville, Louisville, KY, USA.

CORRESPONDENCE D. Gozal

Dept of Paediatrics, Comer Children's Hospital, Pritzker School of Medicine University of Chicago; $5721 \mathrm{~S}$. Maryland Avenue MC 8000

Suite K-160 Chicago IL 60637 USA

E-mail: dgozal@ peds.bsd.uchicago.edu

Received

May 082009

Accepted after revision: July 032009 First published online: July 162009 
be elevated and serve as potential predictors of cardiovascular risk in children with OSA.

\section{SUBJECTS AND METHODS Subjects}

The study was approved by the University of Louisville Human Research Committee (Louisville, KY, USA), and informed consent was obtained from the legal caregiver of each participant. Consecutive children with a diagnosis of OSA according to polysomnographic criteria and aged between 510 yrs were invited to participate in the study. In addition, age-, sex- and ethnicity-matched healthy non-snoring children without OSA who underwent overnight polysomnography were also invited to participate in the study. Children were excluded if they had known diabetes or pre-diabetes [23], any defined genetic abnormality or underlying systemic disease, or if they were within acute infectious processes. The diagnosis of children with mild and moderate-to-severe OSA was defined by the presence of an obstructive apnoea/hypopnoea index (AHI) $\geqslant 1$ per hour of total sleep time (TST) and AHI $\geqslant 5$ per hour of TST, respectively. Control children had AHI $<1$ per hour of TST.

\section{Anthropometry}

Children were weighed on a calibrated scale to the nearest $0.1 \mathrm{~kg}$ and height (to $0.1 \mathrm{~cm}$ ) was measured with a stadiometer (Holtain, Crymych, UK). Body mass index (BMI) was calculated and BMI Z-score was computed using Center for Disease Control growth standards [24] and online software (www.cdc.gov/epiinfo). A BMI Z-score $>1.65$ ( $>95^{\text {th }}$ percentile) was considered as fulfilling obesity criteria.

\section{Overnight polysomnographic evaluation}

Children were studied for $\leqslant 12 \mathrm{~h}$ in a quiet, darkened room with an ambient temperature of $24^{\circ} \mathrm{C}$ in the company of one of their parents. No drugs were used to induce sleep. The following parameters were measured during the overnight sleep recordings: chest and abdominal wall movement by respiratory impedance or inductance plethysmography; heart rate by ECG; and air flow, which was monitored in triplicate with a side-stream end-tidal capnograph, which also provided breath-by-breath assessment of end-tidal carbon dioxide levels (SC-300; BCI, Menomonee Falls, WI, USA), a nasal pressure cannula, and an oronasal thermistor. Arterial oxygen saturation measured by pulse oximetry $\left(\mathrm{Sp}, \mathrm{O}_{2}\right)$ was assessed (Nellcor N 100; Nellcor Inc., Hayward, CA, USA), with simultaneous recording of the pulse waveform. The following were also monitored: bilateral electrooculogram; eight channels of electroencephalogram; chin and anterior tibial electromyograms; and analog output from a body-position sensor (Braebon Medical Corp, Ogdensburg, NY, USA). All measures were digitised with a commercially available polysomnography system (Sandman ${ }_{\circledast}$; Nellcor Puritan Bennett, Kanata, ON, Canada or Stellate Instruments, Montreal, QC, Canada). Tracheal sound was monitored with a microphone sensor (Sleepmate, Midlothian, VA, USA) and a digital time-synchronised video recording was performed. All of the studies were initially scored by a certified technician and were then reviewed by a physician who was experienced in paediatric polysomnography and underwent training in an accredited fellowship programme.
Sleep architecture was assessed by standard techniques [25]. Central, obstructive and mixed apnoeic events were counted. Obstructive apnoea was defined as the absence of airflow with continued chest wall and abdominal movement for duration of at least two breaths [26, 27]. Hypopnoeas were defined as a decrease in oronasal flow of $\geqslant 50 \%$ with a corresponding decrease in $\mathrm{Sp}_{1} \mathrm{O}_{2}$ of $\geqslant 4 \%$ and/or an arousal $[27,28]$. The obstructive AHI was defined as the number of obstructive apnoeas and hypopnoeas per hour of TST. Arousals were identified as defined by the American Sleep Disorders Association Task Force report [28, 29].

\section{Endothelial function tests}

Endothelial function was assessed with a newly developed reactive hyperaemic test after cuff-induced occlusion of the brachial artery [3, 22]. In brief, a laser Doppler sensor (Periflux 5000 system integrated with the PF 5050 pressure unit; Perimed $\mathrm{AB}$, Järfälla, Sweden) was applied over the volar aspect of the hand at the second-finger distal metacarpal surface, and the hand was gently immobilised. Once cutaneous blood flow over the area was stable, the pressure within an inflatable cuff placed distal to the elbow and connected to a computer-controlled manometer was increased to 160$180 \mathrm{mmHg}$ for $60 \mathrm{~s}$, during which time blood flow was reduced to undetectable levels. To enable consistent deflation times, the cuff was deflated under computer control and hyperaemic responses were assessed. Time to peak blood flow following relief of occlusion was considered as representative of the post-occlusion hyperaemic response.

\section{Plasma interleukin-6, C-reactive protein and MRP8/14 levels and serum lipids}

Fasting blood samples were obtained by venipuncture in the morning after the sleep study. Blood samples were immediately centrifuged and frozen at $-80^{\circ} \mathrm{C}$ until assay. Plasma MRP8/14 and interleukin (IL)-6 levels were measured using a commercial ELISA kits (ALPCO Diagnostics, Salem, NH, USA and R\&D systems, Minneapolis, MN, USA for MRP8/14 and IL-6, respectively). MRP8/14 and IL-6 assay have a sensitivity of $0.4 \mathrm{ug} \cdot \mathrm{mL}^{-1}$ and $0.15 \mathrm{pg} \cdot \mathrm{mL}^{-1}$, respectively. The inter-assay and intra-assay of coefficients of variability for MRP8/14 were $4.8 \%$ and $5.3 \%$, respectively. For IL-6, the assay has an intraassay coefficient of variability of $5.8 \%$ and an inter-assay coefficient of variability of $8.2 \%$. C-reactive protein (CRP) was measured within 2-3 h after collection using the Flex reagent cartridge (Date Behring, Newark, DE, USA), which is based on a particle-enhanced turbidimetric immunoassay technique. This method has a detection level of $0.05 \mathrm{mg} \cdot \mathrm{dL}^{-1}$ and exhibits linear behaviour up to $255 \mathrm{mg} \cdot \mathrm{dL}^{-1}$, with intra-assay and interassay coefficients of variability of $9 \%$ and $18 \%$, respectively. Serum levels of lipids, including total cholesterol, high-density lipoprotein, calculated low-density lipoprotein and triglycerides were also assessed with a Flex reagent cartridge (Date Behring).

\section{Statistical analysis}

Data are presented as mean \pm SD or mean \pm SE as indicated. Significant differences within groups were analysed using ANOVA for continuous variables and Chi-squared tests for categorical variables. Bonferroni corrections were applied for multiple comparisons. The distribution of data was assessed 
by the Kolmogorov-Smirnov test. If the data were not normally distributed data were logarithmically transformed. Because obesity would be expected to contribute to increase inflammatory markers, correlation and partial correlation analyses between $\mathrm{AHI}$ and inflammatory markers were performed after adjusting for age and BMI Z-score. We also performed univariate and stepwise multivariate linear regression treating MRP8/14 levels as a dependent variable in relation to $\mathrm{AHI}$ and other covariates. In addition, we used a logistic regression model to estimate the odds ratio of OSA with its $95 \%$ confidence intervals after the population was subdivided into groups based on tertile cut-off points for the distribution of MRP8/14 levels. After controlling for age, sex, race and BMI Z-score we estimated the odds ratios of OSA according to tertile of MRP8/14 levels. Statistical analyses were performed using SPSS software (version 16.0; SPPS Inc., Chicago, IL, USA). All p-values reported are two-tailed with statistical significance set at $<0.05$.

\section{RESULTS}

\section{Study population}

255 children out of 278 eligible children who underwent nocturnal polysomnogram studies were recruited and included in this study. The 23 children who refused to participate did not differ in any recognisable way from the participants. Based on the presence or absence of habitual snoring and AHI, 106 children had mild OSA, 34 had moderate-to-severe OSA and 115 were controls. The demographic, polysomnographic and biochemical characteristics are shown in table 1 . Mean age, sex and ethnic distribution were similar across the three groups $(p>0.05)$. However, log CRP, $\log$ IL-6 and $\log$ MRP8/16 levels showed significant group differences. Moreover, children with severe-to-moderate OSA $(\mathrm{n}=15 ; 41.9 \pm 24.4 \mathrm{~s})$ had delayed peak hyperaemic responses compared to either control children $(n=56 ; 36.8 \pm 21.1 \mathrm{~s})$ or those with mild OSA ( $n=67 ; 36.6 \pm 19.6 \mathrm{~s})$.

\section{MRP levels according to severity of OSA based on the presence of obesity}

Log MRP levels were stratified according to the severity of OSA and the presence or absence of obesity (fig. 1). As shown in figure 1, increases of $\log$ MRP8/14 levels among groups based on AHI categories emerged regardless of obesity. Moreover, moderate-to-severe OSA children had the highest $\log$ MRP levels compared with those of controls of both obese and non-obese children: controls versus moderate-to-severe OSA in obese children $0.02 \pm 0.29$ versus $0.20 \pm 0.18(\mathrm{p}<0.010)$ and in non-obese children $-0.21 \pm 0.34$ versus $0.11 \pm 0.36$ $(\mathrm{p}<0.01)$.

\section{MRP8/14, high-sensitivity CRP and IL-6 in children with OSA}

To estimate potential associations between various inflammatory markers and polysomographic measures we performed correlation analyses. A significant linear correlation between $\log$ MRP and $\log$ AHI $(r=3.40, p<0.001)$ (fig. 2) and an inverse correlation with $\mathrm{Sa}_{2} \mathrm{O}_{2}$ nadir $(\mathrm{r}=-0.23, \mathrm{p}<0.001)$ emerged. Both $\log$ CRP and log IL-6 were also positively correlated with log AHI $(n=112, r=0.25, p<0.01$ and $n=81, r=0.28, p<0.05$, respectively) Furthermore, log MRP8/14 levels were not only significantly correlated with BMI Z-score $(r=0.38, p<0.001)$ (table 2), but also highly associated with $\log$ CRP $(n=112$, $\mathrm{r}=0.63, \mathrm{p}<0.001)($ table 2$)$ and $\log$ IL-6 $(\mathrm{n}=81, \mathrm{r}=0.41, \mathrm{p}<0.001)$ (table 2 ). In addition, we performed partial correlation analysis with BMI Z-scores as a covariate because obesity would be expected to contribute to increased levels of CRP and MRP8/ 14 levels. Both log CRP and log MRP8/14 levels were

TABLE 1 General characteristics of children with obstructive sleep apnoea (OSA) and healthy controls

\begin{tabular}{|c|c|c|c|}
\hline & Control & Mild OSA & Moderate-to-severe OSA \\
\hline Subjects $n$ & 115 & 106 & 34 \\
\hline Age yrs & $7.81 \pm 1.44$ & $7.65 \pm 1.55$ & $7.20 \pm 1.69$ \\
\hline Males \% & 55.7 & 60.4 & 61.8 \\
\hline Caucasian \% & 64.3 & 61.3 & 55.9 \\
\hline BMI Z-score & $1.15 \pm 1.22^{\star \star}$ & $1.32 \pm 1.39^{5}$ & $1.97 \pm 1.1^{\# \#}$ \\
\hline Respiratory arousal index events $\cdot h^{-1}$ & $5.2 \pm 7.3$ & $6.9 \pm 7.8$ & $8.3 \pm 5.2$ \\
\hline Total cholesterol ${ }^{\#} \mathrm{mg} \cdot \mathrm{dL}^{-1}$ & $159.3 \pm 25.1^{*}$ & $168.2 \pm 27.2$ & $181.3 \pm 44.8^{f}$ \\
\hline HDL cholesterol ${ }^{\#} \mathrm{mg} \cdot \mathrm{dL}^{-1}$ & $50.1 \pm 10.2$ & $52.6 \pm 11.6$ & $49.0 \pm 12.7$ \\
\hline LDL cholesterol ${ }^{\#} \mathrm{mg} \cdot \mathrm{dL}^{-1}$ & $92.6 \pm 22.9^{*}$ & $100.2 \pm 22.6$ & $110.1 \pm 37.5$ \\
\hline Triglycerides $^{\#} \mathrm{mg} \cdot \mathrm{dL}^{-1}$ & $82.7 \pm 43.1^{*}$ & $76.1 \pm 35.1$ & $111.2 \pm 78.0$ \\
\hline Peak hyperaemic response ${ }^{\#} \mathbf{s}$ & $36.8 \pm 21.1$ & $36.6 \pm 19.6$ & $41.9 \pm 24.4$ \\
\hline
\end{tabular}

Data are presented as mean \pm SD, unless otherwise stated. Log data are presented as log (absolute) mean \pm SD. BMI; body mass index; AHI: apnoea/hypopnoea index $\mathrm{Sa}, \mathrm{O}_{2}$ : arterial oxygen saturation; HDL: high-density lipoprotein; LDL: low-density lipoprotein; IL: interleukin; hsCRP: high sensitivity C-reactive protein; MRP8/14: myeloid-

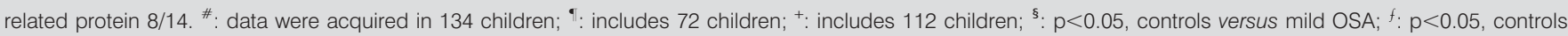
versus moderate-to-severe OSA; ${ }^{\# *}: p<0.01$, controls versus moderate-to-severe OSA. ${ }^{*}: p<0.05,{ }^{* \star}: p<0.01$, differences between three groups (ANOVA test). 

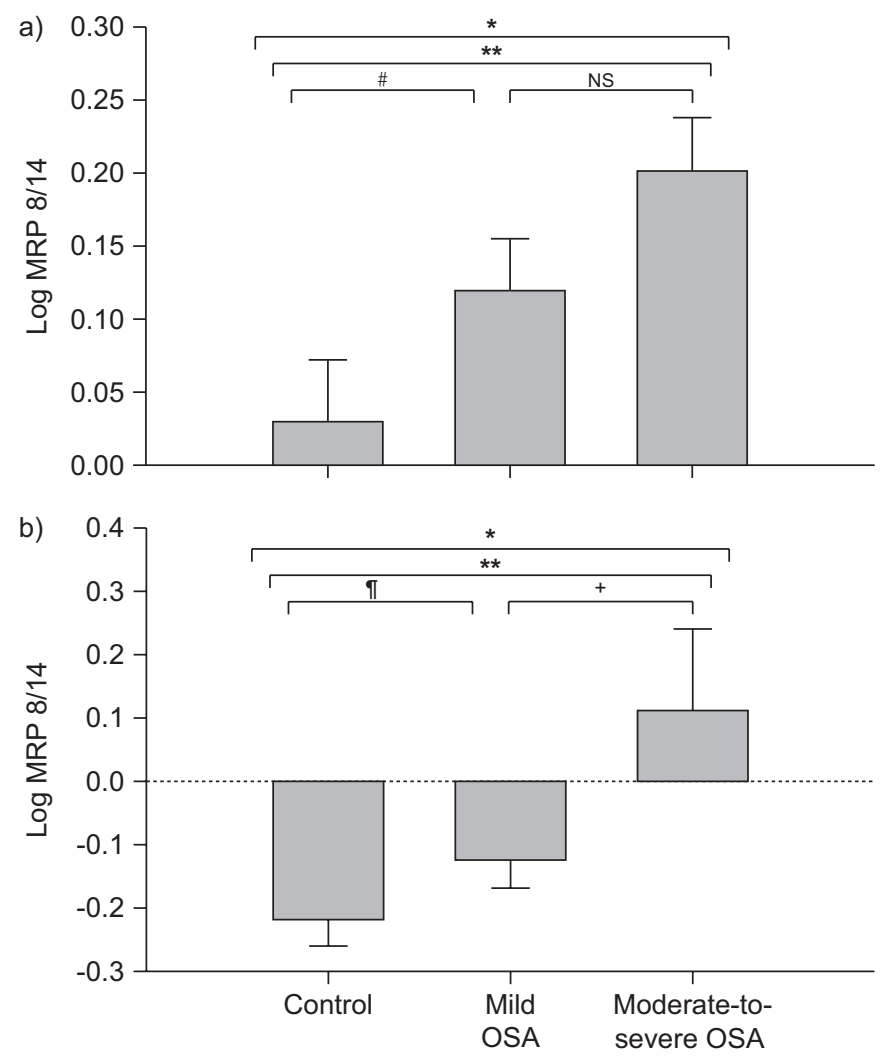

FIGURE 1. Log myeloid-related protein (MRP) $8 / 14$ levels in children with obstructive sleep apnoea (OSA) and controls among a) obese and b) non-obese children. Obesity was defined as a body mass index Z-score $>1.65$. Data are expressed as mean \pm SE. a) Controls: $n=48$; mild OSA: $n=54$; moderate-to-severe OAS: $n=26$. b) Controls: $n=67$; mild OSA: $n=52$; moderate-to-severe OSA: $n=8$. NS: nonsignificant. ${ }^{*}: p=0.08 ;{ }^{\natural}: p=0.13 ;{ }^{+}: p=0.06{ }^{*}: p<0.05 ;{ }^{* *}: p<0.001$.

independently associated with $\log \mathrm{AHI}$, even after controlling for age and BMI Z-score. Furthermore, log MRP8/14 levels showed slightly higher correlation coefficients with $\log$ AHI than those of $\log \mathrm{CRP}(\mathrm{r}=0.29, \mathrm{p}<0.001$ and $\mathrm{r}=0.24, \mathrm{p}<0.05$ for $\log$ MRP8/14 and log CRP, respectively).

\section{MRP8/14 levels and endothelial function}

Log MRP8/14 levels were significantly positively correlated with post-occlusive hyperaemic responses as a surrogate marker of endothelial function $(\mathrm{n}=138, \mathrm{r}=0.25, \mathrm{p}<0.001)$. However, this association did not persist after adjusting for age and BMI Z-score. Peak hyperaemic responses were correlated with BMI Z-score $(n=138, r=0.326, p<0.001)$, but were not significantly correlated with lipid profiles and polysomnographic measures $(\mathrm{p}>0.05)$.

\section{Stepwise multiple regression analysis in OSA children}

To examine independent predictors of MRP8/14 levels in children we performed a stepwise multiple regression analysis (table 3). The strongest predictors of MRP8/14 morning concentrations were BMI Z-score $(\mathrm{p}<0.001)$ and AHI $(\mathrm{p}<0.001)$, which accounted for $24.6 \%$ of variance in MRP8/ 14 level variance, after controlling for age, sex and race.

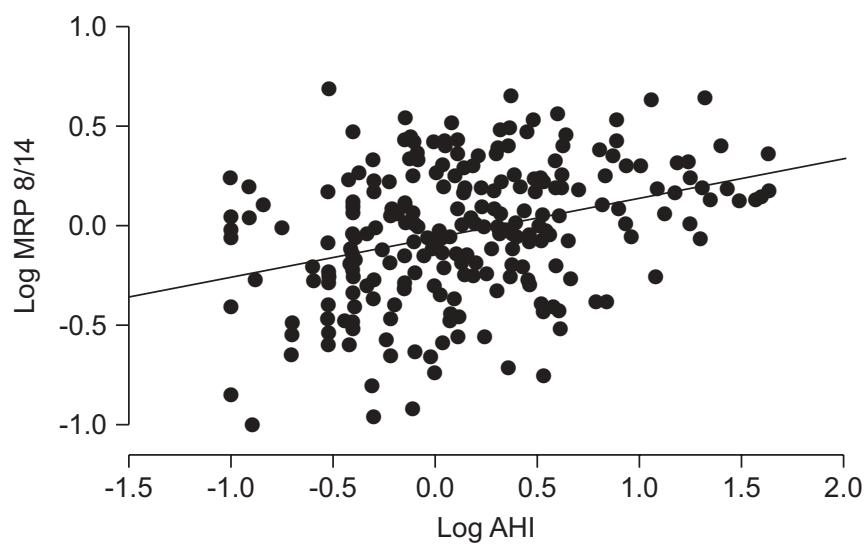

FIGURE 2. Scatter-plot of individual log myeloid-related protein (MRP) 8/14 levels plotted against corresponding log apnoea/hypopnoea index (AHI) levels on overnight polysomnography. $R=0.340 ; p<0.001$.

\section{Odd ratios for OSA according to tertiles of MRP8/14 levels in children}

In order to estimate the odd ratios of OSA in relation to any given MRP8/14 level we performed logistic regression analysis. Table 4 presents univariate and multivariate odd ratios on the likelihood of OSA according to increasing tertiles of MRP8/14 levels. In the univariate model, odd ratios $(95 \%$ confidence intervals) of mild-to-moderate OSA (AHI $\geqslant 5$ events $\left.\cdot \mathrm{h}^{-1}\right)$ were $2.47(95 \%$ CI $1.26-4.85$; $\mathrm{p}<0.05)$ for the second tertile of MRP8/14 $\left(0.706-1.34 \mu \mathrm{g} \cdot \mathrm{mL}^{-1}\right)$ and $7.68(95 \%$ CI 2.57-22.9; $\mathrm{p}<0.01$ ) for the third tertile of MRP8/14 $\left(>1.34 \mu \mathrm{g} \cdot \mathrm{mL}^{-1}\right)$ using the lowest MRP8/14 tertile level as reference. After adjusting for confounding factors such as age, SEX, race and BMI z-score, children in the highest tertile of MRP8/14 levels had a 5.6-fold increased risk (95\% CI 1.64-17.1, $\mathrm{p}<0.01$ ) for moderate-to-severe OSA compared to those whose MRP8/14 levels were within the lower range.

\section{DISCUSSION}

In the present study, we found that both obese children and children with OSA have elevated plasma MRP8/14 levels. Furthermore, MRP8/14 levels are dose-dependently increased relative to the severity of OSA, even in non-obese children. Moreover, MRP8/14 levels were not only highly correlated with CRP and IL-6, but were also correlated to endothelial function. Even after adjusting for potential confounding factors, both AHI and BMI were independently associated with MRP8/14 levels. Moreover, children in the highest tertile of MRP8/14 levels were at markedly higher risk (5.6-fold) for moderate-to-severe OSA.

Increasing evidence suggests the presence of increased risk for endothelial dysfunction and other adverse cardiovascular consequences in both adults and children with OSA $[3,7,8$, 30-32]. While the definite mechanisms are yet to be delineated, production of vasoactive substances, such as endothelin-1 by endothelial cells, may be altered [33-35], along with reductions in nitric oxide availability and potentially increases in circulating levels of endogenous inhibitors of nitric oxide synthase [36-38]. Two major, and to some extent overlapping mechanisms, namely increased generation and propagation of reactive oxygen species and amplification of inflammatory 


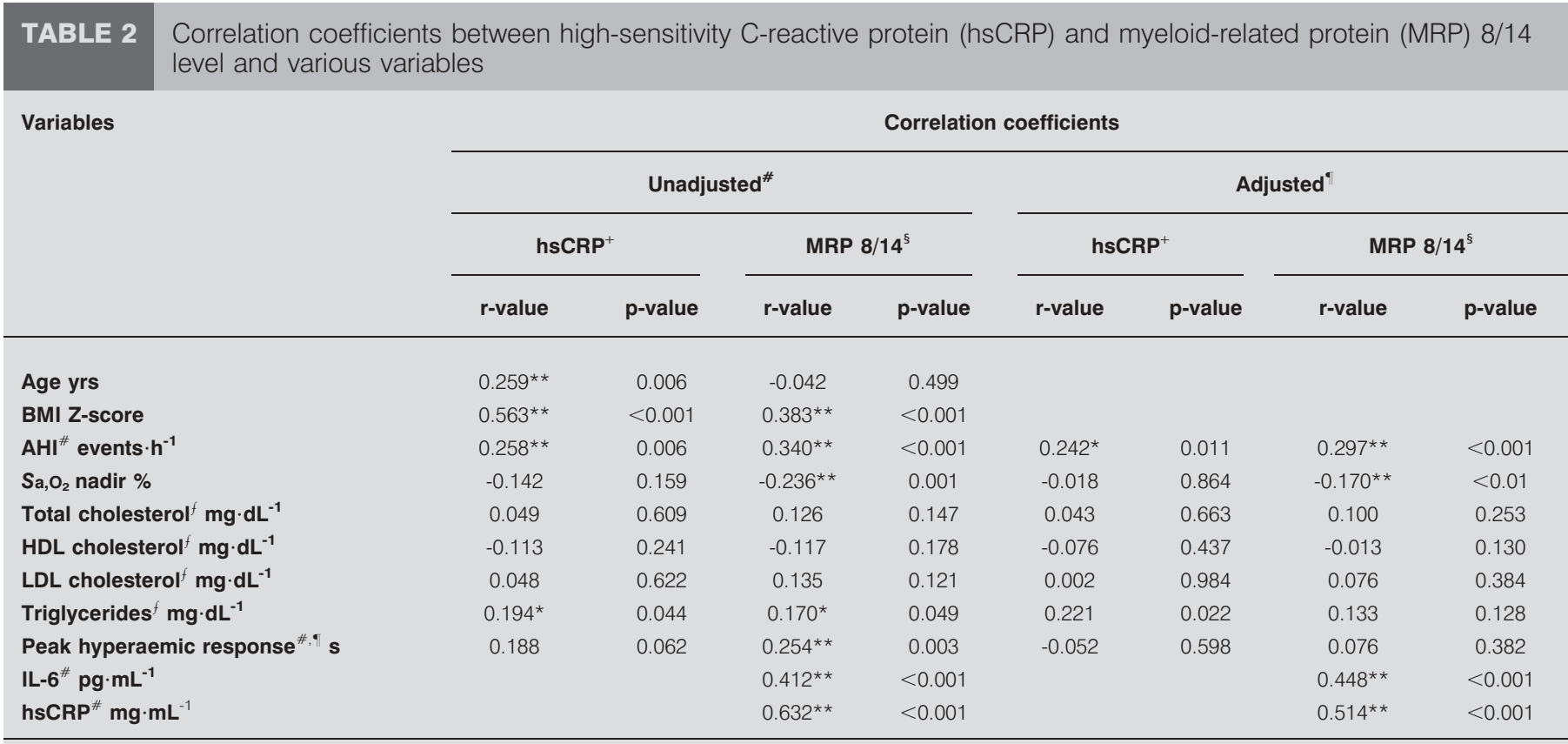

BMI: body mass index; AHI: apnoea/hypopnoea index; Sa, $\mathrm{O}_{2}$ : arterial oxygen saturation; HDL: high-density lipoprotein; LDL: low-density lipoprotein; IL: interleukin. ${ }^{*}$ : data were log-transformed; ${ }^{\bullet}$ : data were adjusted for age and BMI Z-score; ${ }^{*}: n=112 ;{ }^{\varsigma}: n=225 ;{ }^{f}$ : data were included for 112 children. ${ }^{*}: p<0.05 ;{ }^{* \star}: p<0.01$.

processes, may underlie such changes along with increasing the adherence of inflammatory mediators to endothelial cells and hypercoagulability [1, 5, 8, 19, 30, 39-42]. Hyperactivation and increased reactivity of the sympathetic system have been reported in children with OSA [43-45] and systemic blood pressure elevations are not only OSA-severity dependent [4648 ], but are also associated with altered left ventricular geometry and contractibility [49]. Recently, we reported that children with sleep-disordered breathing have elevated plasma IL-6 and P-selectin levels [41, 50]. Moreover, CRP, an important circulating marker of inflammation, is elevated in children with OSA and reduced after tonsillectomy [21, 51], even if not consistently [52, 53], suggesting that the determinants of CRP elevation in the presence of OSA do not

\begin{tabular}{|c|c|c|c|c|c|c|}
\hline TABLE 3 & $\begin{array}{l}\text { Associ } \\
\text { and } m y \\
\text { and co }\end{array}$ & $\begin{array}{l}n \text { of } \\
\text { id-re } \\
\text { iates }\end{array}$ & ted prot & $\begin{array}{l}\text { opno } \\
\text { ר (MF }\end{array}$ & $\begin{array}{l}\text { inde } \\
8 / 1\end{array}$ & $\begin{array}{l}\text { (AHI) } \\
\text { evels }\end{array}$ \\
\hline \multirow{3}{*}{$\begin{array}{l}\text { Independent } \\
\text { variables }\end{array}$} & \multicolumn{6}{|c|}{ MRP $8 / 14^{\#}$} \\
\hline & \multicolumn{3}{|c|}{ Univariate } & \multicolumn{3}{|c|}{ Stepwise multivariate } \\
\hline & $\beta$ & $\mathrm{SE}$ & $\mathrm{p}$-value & $\beta$ & $\mathrm{SE}$ & $\mathrm{p}$-value \\
\hline Age & -0.25 & 0.01 & 0.67 & & & \\
\hline Sex & 0.001 & 0.03 & 0.92 & & & \\
\hline Race & 0.12 & 0.02 & 0.04 & & & \\
\hline BMI Z-score & 0.32 & 0.01 & $<0.001$ & 0.31 & 0.01 & $<0.001$ \\
\hline $\mathbf{A H I}^{\#}$ & 0.27 & 0.03 & $<0.001$ & 0.28 & 0.03 & $<0.001$ \\
\hline
\end{tabular}

BMI: body mass index. ${ }^{*}$ : data were log-transformed exclusively account for the severity of the condition but are also dictated by other factors. Notwithstanding, this study further confirms our previous findings. More importantly, both MRP8/14 and CRP showed significant associations with AHI, even after adjustment for age and BMI Z-score, with the latter being an important risk factor for cardiovascular morbidity [54]. The interactions between the severity of OSA, lifestyle patterns, environmental conditions and genetically driven individual susceptibility have probably all involved the magnitude of the inflammatory responses associated with OSA $[3,6,30]$. Therefore, more specific assessment of these factors as they relate to MRP8/14 in the context of paediatric OSA need to be performed in the future.

MRP8/14 is a major calcium binding protein and is primarily expressed in cells of myeloid origin, particularly in monocytes and neutrophils [11-13]. Upon phagocyte activation, MRP 8 and MRP 14 will form the MRP 8/14complex, which translocates to the cytoskeleton and plasma membrane where it is secreted [11, 12]. This is an early event during the process of transendothelial migration and interaction of MRP-expressing neutrophils and monocytes with the endothelium [55, 56]. However, the physiological roles of MRP8/14 are not well characterised. Notwithstanding, elevated MRP8/14 levels are useful biomarkers of disease activity, such as in rheumatoid arthritis and inflammatory bowel disease [57, 58]. MRP8/14 levels may also play an important pathophysiological role in cardiovascular disease and in diabetic complications [15, 16, 18, 59, 60]. Indeed, BURKHARTDT et al. [61] suggested that MRP8/14 levels not only serve as reliable reporters on the state of inflammation in diabetic nephropathy, but also on the degree of microvascular dysfunction within the glomerular and retinal beds. Furthermore, ALTWEGG et al. [59] reported that MRP8/14 is markedly expressed at the site of coronary 


\begin{tabular}{|c|c|c|c|c|c|}
\hline \multirow[t]{3}{*}{ TABLE 4} & \multicolumn{5}{|c|}{$\begin{array}{l}\text { Logistic regression analysis on the association of obstructive sleep apnoea (OSA) and myeloid-related protein (MRP) } 8 / 14 \\
\text { tertile levels in children }\end{array}$} \\
\hline & & \multirow[t]{2}{*}{ OSA n } & \multicolumn{3}{|c|}{ Tertile of MRP $8 / 14$} \\
\hline & & & $\begin{aligned} & 1^{\text {st }} \text { tertile }{ }^{\#}: \\
< & 0.705 \mu \mathrm{g} \cdot \mathrm{mL}^{-1}\end{aligned}$ & $\begin{array}{l}2^{\text {nd }} \text { tertile }: \\
0.706-1.34 \mu \mathrm{g} \cdot \mathrm{mL}^{-1}\end{array}$ & $\begin{aligned} & 3^{\text {rd }} \text { tertile } e^{+}: \\
> & 1.34 \mu \mathrm{g} \cdot \mathrm{mL}^{-1}\end{aligned}$ \\
\hline Moderate- & -severe OSA versus control & 34 & 1.0 & $2.40(1.16-4.95)^{\star \star}$ & $5.30(1.64-17.1)^{\star \star}$ \\
\hline \multicolumn{6}{|c|}{ Univariate OR $(95 \% \mathrm{Cl})$} \\
\hline Mild OSA & ersus control & 106 & 1.0 & $1.29(0.68-2.43)$ & $2.05(0.63-6.6)$ \\
\hline Moderate- & -severe OSA versus control & 34 & 1.0 & $2.47(1.26-4.85)^{*}$ & $7.68(2.57-22.9)^{* *}$ \\
\hline
\end{tabular}

Logistic regression analysis was used to estimate $\mathrm{OR}$ and $95 \% \mathrm{Cl}$ after the cohort was divided into three groups based on tertile cut-off points according to the distribution

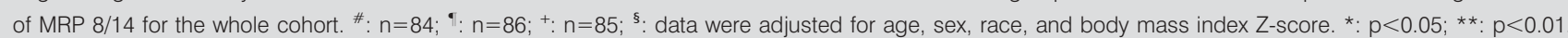

occlusion by invading phagocytes. These investigators found that MRP8/14 levels are increased in the systemic circulation well before elevation of other markers of myocardial damage, such as myoglobin, creatine kinase MB isoform and troponin. MorRow et al. [15] also showed that patients with elevated levels of both MRP8/14 and CRP have a two-fold increased risk of cardiovascular death or of suffering a myocardial infarction compared with matched patients in whom these markers are not increased. Herein, we observed that children with highest tertile MRP8/14 levels had a 5.3-fold increase risk of moderate-to-severe OSA even after controlling for confounding factors. Moreover, plasma MRP8/14 levels were significantly correlated with both CRP and IL-6 circulating levels. Therefore, plasma MRP8/14 levels may not only provide a reliable marker of OSA and of the magnitude of the inflammatory response in the context of OSA, but may also be indicative of particular populations at increased risk for development of cardiovascular complications. However, this is the first report on the association between MRP8/14 and OSA, and these initial observations will need to be confirmed by more extensive prospective interventional studies.

Some methodological considerations deserve comment. First, the relative contribution of upper airway tissues such as tonsils and adenoids to the increase in inflammatory markers can not be ascertained [62]. Secondly, since MRP8/14 can be highly expressed in different cell types [16, 63], it will be important to determine which cells populations are more specifically involved the inflammatory responses in paediatric OSA and account for the OSA-associated increases in MRP8/14 levels. Thirdly, we can not exclude the possibility of existing contributions to MRP8/14 levels by underlying metabolic dysfunction, particularly considering reports on elevated plasma levels of MRP8/14 in the context of diabetes mellitus $[60,61]$. However, all children included in this study did not have diabetes or any other systemic disease. Fourthly, there is some uncertainty as to the association between post-occlusive hyperaemic responses and MRP8/14 levels, and more in-depth studies on this topic are needed. Of note, we have previously uncovered that the presence of a strong family history of ischaemic heart disease was significantly associated with persistence of endothelial dysfunction in children with OSA, even after treatment of OSA [22]. Unfortunately, we did not explore the cardiovascular family history in the present study. Finally, we did not assess the reversibility of MRP8/14 elevations after effective treatment of OSA, nor did we examine the dynamic changes in MRP8/14 levels in the course of the night.

In summary, children with OSA have elevated morning plasma MRP8/14 levels which exhibit OSA severity-related dependencies, even among non-obese children. Additional studies are needed to examine the intrinsic contributions to the clinical practice of assessing MRP8/14 levels in the context of evaluating children at risk for OSA.

\section{SUPPORT STATEMENT}

This work was funded by a National Institute of Health grant (HL65270).

\section{STATEMENT OF INTEREST}

Statements of interest for R. Bhattacharjee, L. Kheirandish-Gozal and D. Gozal can be found at www.erj.ersjournals.com $/ \mathrm{misc} /$ statements.dtl

\section{REFERENCES}

1 Kushida CA, Chediak A, Berry RB, et al. Clinical guidelines for the manual titration of positive airway pressure in patients with obstructive sleep apnea. J Clin Sleep Med 2008; 4: 157-171.

2 Shamsuzzaman AS, Gersh BJ, Somers VK. Obstructive sleep apnea: implications for cardiac and vascular disease. JAMA 2003; 290: 1906-1914.

3 Bhattacharjee R, Kheirandish-Gozal L, Pillar G, et al. Cardiovascular complications of obstructive sleep apnea syndrome: evidence from children. Prog Cardiovasc Dis 2009; 51: 416-433.

4 Gozal D, Capdevila OS, Kheirandish-Gozal L. Metabolic alterations and systemic inflammation in obstructive sleep apnea among nonobese and obese prepubertal children. Am J Respir Crit Care Med 2008; 177: 1142-1149.

5 Capdevila OS, Kheirandish-Gozal L, Dayyat E, et al. Pediatric obstructive sleep apnea: complications, management, and longterm outcomes. Proc Am Thorac Soc 2008; 5: 274-282.

6 Tauman R, Gozal D. Obesity and obstructive sleep apnea in children. Paediatr Respir Rev 2006; 7: 247-259.

7 Atkeson A, Yeh SY, Malhotra A, et al. Endothelial function in obstructive sleep apnea. Prog Cardiovasc Dis 2009; 51: 351-362. 
8 Jelic S, Le Jemtel TH. Inflammation, oxidative stress, and the vascular endothelium in obstructive sleep apnea. Trends Cardiovasc Med 2008; 18: 253-260.

9 Hatipoglu U, Rubinstein I. Inflammation and obstructive sleep apnea syndrome pathogenesis: a working hypothesis. Respiration 2003; 70: 665-671.

10 Ahmad A, Bayley DL, He S, et al. Myeloid related protein-8/14 stimulates interleukin-8 production in airway epithelial cells. Am J Respir Cell Mol Biol 2003; 29: 523-530.

11 Rammes A, Roth J, Goebeler M, et al. Myeloid-related protein (MRP) 8 and MRP14, calcium-binding proteins of the S100 family, are secreted by activated monocytes via a novel, tubulindependent pathway. J Biol Chem 1997; 272: 9496-9502.

12 Stroncek DF, Shankar RA, Skubitz KM. The subcellular distribution of myeloid-related protein 8 (MRP8) and MRP14 in human neutrophils. J Transl Med 2005; 3: 36.

13 Pouliot P, Plante I, Raquil MA, et al. Myeloid-related proteins rapidly modulate macrophage nitric oxide production during innate immune response. J Immunol 2008; 181: 3595-3601.

14 Guignard F, Mauel J, Markert M. Phosphorylation of myeloidrelated proteins MRP-14 and MRP-8 during human neutrophil activation. Eur J Biochem 1996; 241: 265-271.

15 Morrow DA, Wang Y, Croce K, et al. Myeloid-related protein 8/14 and the risk of cardiovascular death or myocardial infarction after an acute coronary syndrome in the Pravastatin or Atorvastatin Evaluation and Infection Therapy: Thrombolysis in Myocardial Infarction (PROVE IT-TIMI 22) trial. Am Heart J 2008; 155: 49-55.

16 Healy AM, Pickard MD, Pradhan AD, et al. Platelet expression profiling and clinical validation of myeloid-related protein-14 as a novel determinant of cardiovascular events. Circulation 2006; 113: 2278-2284.

17 Eue I, Langer C, Eckardstein A, et al. Myeloid related protein (MRP) 14 expressing monocytes infiltrate atherosclerotic lesions of ApoE null mice. Atherosclerosis 2000; 151: 593-597.

18 Viemann D, Strey A, Janning A, et al. Myeloid-related proteins 8 and 14 induce a specific inflammatory response in human microvascular endothelial cells. Blood 2005; 105: 2955-2962.

19 Gozal D, Serpero LD, Sans Capdevila O, et al. Systemic inflammation in non-obese children with obstructive sleep apnea. Sleep Med 2008; 9: 254-259.

20 Gozal D, Crabtree VM, Sans Capdevila O, et al. C-reactive protein, obstructive sleep apnea, and cognitive dysfunction in school-aged children. Am J Respir Crit Care Med 2007; 176: 188-193.

21 Tauman R, Ivanenko A, O'Brien LM, et al. Plasma C-reactive protein levels among children with sleep-disordered breathing. Pediatrics 2004; 113: e564-e569.

22 Gozal D, Kheirandish-Gozal L, Serpero LD, et al. Obstructive sleep apnea and endothelial function in school-aged nonobese children: effect of adenotonsillectomy. Circulation 2007; 116: 2307-2314.

23 American Diabetes Association. Diabetes basics. Symptoms. Available from: www.diabetes.org/pre-diabetes/pre-diabetessymptoms.jsp Date last accessed: February 9, 2010.

24 Centers for Disease Control and Prevention. CDC Growth Charts. Available from: www.cdc.gov/growthcharts Date last updated: August 4, 2009; date last accessed: February 9, 2010.

25 Rechstschaffen A., Kales A, eds. A Manual of Standardized Terminology, Techniques and Scoring System for Sleep Stages of Human Subjects. Los Angeles, Brain Information Services/Brain Research Institute, 1968.

26 Standards and indications for cardiopulmonary sleep studies in children. American Thoracic Society. Am J Respir Critical Care Med 1996; 153: 866-878.

27 Montgomery-Downs HE, O'Brien LM, Gulliver TE, et al. Polysomnographic characteristics in normal preschool and early school-aged children. Pediatrics 2006; 117: 741-753.
28 The AASM Manual for the Scoring of Sleep and Associated Events. Rules, Terminology and Technical Specifications. Westchester, American Academy of Sleep Medicine, 2007.

29 EEG arousals: scoring rules and examples: a preliminary report from the Sleep Disorders Atlas Task Force of the American Sleep Disorders Association. Sleep 1992; 15: 173-184.

30 Gozal D, Kheirandish-Gozal L. Cardiovascular morbidity in obstructive sleep apnea: oxidative stress, inflammation, and much more. Am J Respir Crit Care Med 2008; 177: 369-375.

31 Gozal D, Kheirandish L. Oxidant stress and inflammation in the snoring child: confluent pathways to upper airway pathogenesis and end-organ morbidity. Sleep Med Rev 2006; 10: 83-96.

32 Somers VK, White DP, Amin R, et al. Sleep apnea and cardiovascular disease: an American Heart Association/American College of Cardiology Foundation Scientific Statement from the American Heart Association Council for High Blood Pressure Research Professional Education Committee, Council on Clinical Cardiology, Stroke Council, and Council on Cardiovascular Nursing. J Am Coll Cardiol 2008; 52: 686-717.

33 Saarelainen S, Seppala E, Laasonen K, et al. Circulating endothelin-1 in obstructive sleep apnea. Endothelium 1997; 5: 115-118.

34 Allahdadi KJ, Walker BR, Kanagy NL. Augmented endothelin vasoconstriction in intermittent hypoxia-induced hypertension. Hypertension 2005; 45: 705-709.

35 Gjorup PH, Sadauskiene L, Wessels J, et al. Abnormally increased endothelin-1 in plasma during the night in obstructive sleep apnea: relation to blood pressure and severity of disease. Am J Hypertens 2007; 20: 44-52.

36 Ip MS, Lam B, Chan LY, et al. Circulating nitric oxide is suppressed in obstructive sleep apnea and is reversed by nasal continuous positive airway pressure. Am J Respir Crit Care Med 2000; 162: 2166-2171.

37 Schulz R, Schmidt D, Blum A, et al. Decreased plasma levels of nitric oxide derivatives in obstructive sleep apnoea: response to CPAP therapy. Thorax 2000; 55: 1046-1051.

38 Ohike Y, Kozaki K, Iijima K, et al. Amelioration of vascular endothelial dysfunction in obstructive sleep apnea syndrome by nasal continuous positive airway pressure - possible involvement of nitric oxide and asymmetric NG, NG-dimethylarginine. Circ J 2005; 69: 221-226.

39 Lavie L. Oxidative stress - a unifying paradigm in obstructive sleep apnea and comorbidities. Prog Cardiovasc Dis 2009; 51: 303-312.

40 Yamauchi M, Kimura H. Oxidative stress in obstructive sleep apnea: putative pathways to the cardiovascular complications. Antioxid Redox Signal 2008; 10: 755-768.

41 Tauman R, O'Brien LM, Gozal D. Hypoxemia and obesity modulate plasma C-reactive protein and interleukin-6 levels in sleep-disordered breathing. Sleep Breath 2007; 11: 77-84.

42 Kaditis AG, Alexopoulos EI, Kalampouka E, et al. Morning levels of fibrinogen in children with sleep-disordered breathing. Eur Respir J 2004; 24: 790-797.

43 O'Brien LM, Gozal D. Autonomic dysfunction in children with sleep-disordered breathing. Sleep 2005; 28: 747-752.

44 Baharav A, Kotagal S, Rubin BK, et al. Autonomic cardiovascular control in children with obstructive sleep apnea. Clin Auton Res 1999; 9: 345-351.

45 McConnell K, Somers VK, Kimball T, et al. Baroreflex gain in children with obstructive sleep apnea. Am J Respir Crit Care Med 2009; 180: 42-48.

46 Bixler EO, Vgontzas AN, Lin HM, et al. Blood pressure associated with sleep-disordered breathing in a population sample of children. Hypertension 2008; 52: 841-846.

$47 \mathrm{Li} \mathrm{AM}, \mathrm{Au} \mathrm{CT}$, Sung RY, et al. Ambulatory blood pressure in children with obstructive sleep apnoea: a community based study. Thorax 2008; 63: 803-809. 
48 Amin R, Somers VK, McConnell K, et al. Activity-adjusted 24-hour ambulatory blood pressure and cardiac remodeling in children with sleep disordered breathing. Hypertension 2008; 51: 84-91.

49 Amin RS, Kimball TR, Bean JA, et al. Left ventricular hypertrophy and abnormal ventricular geometry in children and adolescents with obstructive sleep apnea. Am J Respir Crit Care Med 2002; 165: 1395-1399.

50 O'Brien LM, Serpero LD, Tauman R, et al. Plasma adhesion molecules in children with sleep-disordered breathing. Chest 2006; 129: 947-953.

51 Kheirandish-Gozal L, Capdevila OS, Tauman R, et al. Plasma Creactive protein in nonobese children with obstructive sleep apnea before and after adenotonsillectomy. J Clin Sleep Med 2006; 2: 301-304.

52 Kaditis AG, Alexopoulos EI, Kalampouka E, et al. Morning levels of C-reactive protein in children with obstructive sleep-disordered breathing. Am J Respir Crit Care Med 2005; 171: 282-286.

53 Taheri S, Austin D, Lin L, et al. Correlates of serum C-reactive protein (CRP) - no association with sleep duration or sleep disordered breathing. Sleep 2007; 30: 991-996.

54 Ford ES, Galuska DA, Gillespie C, et al. C-reactive protein and body mass index in children: findings from the Third National Health and Nutrition Examination Survey, 1988-1994. J Pediatr 2001; 138: 486-492.

55 Bhardwaj RS, Zotz C, Zwadlo-Klarwasser G, et al. The calciumbinding proteins MRP8 and MRP14 form a membrane-associated heterodimer in a subset of monocytes/macrophages present in acute but absent in chronic inflammatory lesions. Eur J Immunol 1992; 22: 1891-1897.

56 Eue I, Pietz B, Storck J, et al. Transendothelial migration of 27E10+ human monocytes. Int Immunol 2000; 12: 1593-1604.

57 Schulze zur Wiesch A, Foell D, Frosch M, et al. Myeloid related proteins MRP8/MRP14 may predict disease flares in juvenile idiopathic arthritis. Clin Exp Rheumatol 2004; 22: 368-373.

58 Liao $\mathrm{H}, \mathrm{Wu}$ J, Kuhn E, et al. Use of mass spectrometry to identify protein biomarkers of disease severity in the synovial fluid and serum of patients with rheumatoid arthritis. Arthritis Rheum 2004; 50: 3792-3803.

59 Altwegg LA, Neidhart M, Hersberger M, et al. Myeloid-related protein $8 / 14$ complex is released by monocytes and granulocytes at the site of coronary occlusion: a novel, early, and sensitive marker of acute coronary syndromes. Eur Heart J 2007; 28: 941-948.

60 Bouma G, Lam-Tse WK, Wierenga-Wolf AF, et al. Increased serum levels of MRP-8/14 in type 1 diabetes induce an increased expression of $\mathrm{CD} 11 \mathrm{~b}$ and an enhanced adhesion of circulating monocytes to fibronectin. Diabetes 2004; 53: 1979-1986.

61 Burkhardt K, Schwarz S, Pan C, et al. Myeloid-related protein 8/14 complex describes microcirculatory alterations in patients with type 2 diabetes and nephropathy. Cardiovasc Diabetol 2009; 8: 10.

62 Agren K, Andersson U, Nordlander B, et al. Upregulated local cytokine production in recurrent tonsillitis compared with tonsillar hypertrophy. Acta Otolaryngol 1995; 115: 689-696.

63 Nacken W, Roth J, Sorg C, et al. S100A9/S100A8: Myeloid representatives of the $\mathrm{S} 100$ protein family as prominent players in innate immunity. Microsc Res Tech 2003; 60: 569-580. 